\title{
Effects of short photoperiods on puberty, growth and moult in the Djungarian hamster (Phodopus sungorus)
}

\author{
K. Hoffmann \\ Max-Planck-Institut für Verhaltensphysiologie, D-8131 Andechs, West Germany
}

\begin{abstract}
Summary. Male Djungarian hamsters were raised from birth in either long (16L:8D) or short (8L :16D) photoperiods. In $16 \mathrm{~L}: 8 \mathrm{D}$, testes were large (about $400 \mathrm{mg}$ ) and showed full spermatogenesis from 31 days of age, the cauda epididymidis contained motile spermatozoa from 35 days and the accessory glands were large and reached their final size at about 60 days of age. In $8 \mathrm{~L}: 16 \mathrm{D}$, testes remained small (about $15 \mathrm{mg}$ ) and undeveloped up to an age of about 130 days; they then developed to reach normal size and full spermatogenesis. In $16 \mathrm{~L}: 8 \mathrm{D}$ body weight increased steadily up to an age of about 160 days, but in $8 \mathrm{~L}: 16 \mathrm{D}$ body weight increase was slower and reached normal values, after a plateau at about 80 days, at about 190-260 days. Most animals in $8 \mathrm{~L}: 16 \mathrm{D}$ moulted into winter pelage, and then into the summer pelage; those in $16 \mathrm{~L}: 8 \mathrm{D}$ kept the summer pelage throughout.
\end{abstract}

\section{Introduction}

Many mammals show a marked annual cycle in gonadal size and activity as well as in other functions. In a number of species it has been demonstrated that this cycle can be manipulated by photoperiod (for reviews see Aschoff, 1955; Sadleir, 1969; Chapman, 1970; Farner, Lewis \& Darden, 1973; Reiter, 1974). Variations of sexual development, depending on season of birth, have also been reported (see Sadleir, 1969; Lincoln \& MacKinnon, 1976).

Photoperiodic effects in the golden hamster have been studied intensively (Hoffman \& Reiter, 1965; Gaston \& Menaker, 1967; Elliot, 1974). In adults short photoperiods or blinding induce gonadal regression while long photoperiods instigate regrowth. Sexual development in young animals, however, is not influenced by photoperiod (Gaston \& Menaker, 1967; and unpublished experiments). Reiter, Sorrentino \& Hoffman (1970) found no differences of sexual development in golden hamsters blinded soon after birth and intact animals living in long photoperiods.

Similar findings have been reported for adult Djungarian hamsters. Under natural light conditions animals of this species show a marked annual cycle, not only in gonadal size but also in body weight and pelage colour (Figala, Hoffmann \& Goldau, 1973; Hoffmann, 1973). In autumn testes regress to less than one-tenth of their summer size, body weight decreases by about $30 \%$, and the moult results in a whitish winter pelage. All these changes can be instigated by photoperiodic manipulation. Short photoperiods bring about the winter state while long photoperiods cause precocious change into the summer condition (Hoffmann, 1973, 1974, 1978; Hoffmann \& Küderling, 1975, 1977). Because some observations of litters born late in the breeding season suggested that photoperiod might also influence pubertal development in Phodopus, a systematic study of this possibility was undertaken.

\section{Materials and Methods}

All the hamsters were derived from the colony which has been maintained in this laboratory since 1968, and originated from 4 animals caught near Omsk in western Siberia, the northwest of the range of distribution (Flint, 1966). The animals belong to the subspecies Phodopus sungorus sungorus which, under natural illumination, changes into a whitish winter pelage in late autumn (Figala et al., 1973). 
Pairs were kept in plastic cages $(42 \times 28 \times 17 \mathrm{~cm})$ and received a standard diet for breeding hamsters (no. 7010, Altromin GmbH, Lage/Lippe) and water ad libitum. Light conditions were either natural daylight or long artificial photoperiods with $16 \mathrm{~h}$ light/24 h (16L :8D).

Within $48 \mathrm{~h}$ after parturition the adult males were removed, and the females with their litters were placed into one of two corresponding rooms which were kept at a temperature of $20 \pm 1{ }^{\circ} \mathrm{C}$. Light was provided by fluorescent tubes only, the light intensity directly above the cages being between 40 and $600 \mathrm{~lx}$, depending on the position of the cage in the room. No difference in development due to differences in light intensity was observed within this range. Half of the females (and their young) were placed in $16 \mathrm{~L}: 8 \mathrm{D}$ (lights on 04:00-20:00 h) and the others were placed in short photoperiods ( $8 \mathrm{~L}: 16 \mathrm{D}$; lights on $08: 00-16: 00 \mathrm{~h}$ ). The young were weaned at 21 days of age, and males were placed singly in plastic cages $(29 \times 19 \times 15 \mathrm{~cm})$ in the same room and conditions of illumination. Two experiments were performed.

Experiment 1. A total of 190 males maintained in $16 \mathrm{~L}: 8 \mathrm{D}$ and 196 males maintained in $8 \mathrm{~L}: 16 \mathrm{D}$ were killed at various ages between 31 and 75 days. The body weight and pelage colour were noted and testes and accessory glands (seminal vesicles, coagulating glands, ampullary glands) were removed and weighed. Testes were fixed in Bouin, preserved in $80 \%$ alcohol, embedded in Paraplast, sectioned (usually at $10 \mu \mathrm{m}$ ) and stained in Mayer's haemalum and eosin. Smears of the contents of each cauda epididymidis were taken, diluted with $0.154 \mathrm{M}-\mathrm{NaCl}$ solution, and inspected for the presence of spermatozoa. These hamsters were weighed and inspected for pelage colour at intervals of 10 days or more until killed. In addition, 56 males maintained in $16 \mathrm{~L}: 8 \mathrm{D}$ and 34 males maintained in $8 \mathrm{~L}: 16 \mathrm{D}$ were weighed and inspected at various ages.

Experiment 2. In another group of young male hamsters testis size, body weight and pelage colour were noted from 24-34 days of age onward until 280 days age, approximately every 14 days. Testis size was determined by palpation while the animals were under halothane anaesthesia. Four stages of testis size were recognized: Stage $\mathrm{N}=$ testes not palpable (in adult hamsters this stage corresponds to the fully regressed condition found in late autumn and early winter; all animals with undeveloped testes in Exp. 1 were Stage N, compare Text-fig. 1a); Stage $S=$ small testes; Stage $\mathbf{M}=$ testes of medium size, the cauda epididymidis does not contain spermatozoa at that stage; Stage $\mathrm{L}=$ large testes, corresponding to full spermatogenesis (all testes of hamsters raised in $16 \mathrm{~L}: 8 \mathrm{D}$ and older than 38 days in Exp. 1 were Stage L; see Text-fig. 1a).

Forty-two (42) males maintained in $16 \mathrm{~L}: 8 \mathrm{D}$ from birth and 43 males maintained in $8 \mathrm{~L}: 16 \mathrm{D}$ were used. Since the experiment was designed to determine whether puberty is reached at all in short photoperiods, 4 of the original 47 males raised in $8 \mathrm{~L}: 16 \mathrm{D}$ were removed from the experiment because they already showed some testicular development at 28-32 days of age, in spite of the short photoperiods.

\section{Results}

Testes. The testicular weights of the animals killed in Exp. 1 are shown in Text-fig. 1a. Males raised in $16 \mathrm{~L}: 8 \mathrm{D}$ had large testes, weighing about $400 \mathrm{mg}$, while most of those raised in $8 \mathrm{~L}: 16 \mathrm{D}$ had small testes weighing about $15 \mathrm{mg}$. Histological examination showed that the seminiferous tubular diameter was large in the $16 \mathrm{~L}: 8 \mathrm{D}$ animals and generally small in the others (Text-fig. $1 \mathrm{~b}$ ). In the testes of practically all the males kept in long photoperiods full spermatogenesis was observed, but in most males raised in short photoperiods only Sertoli cells, spermatogonia and a few spermatocytes were present. Epididymal smears showed that the cauda epididymidis of the $16 \mathrm{~L}: 8 \mathrm{D}$ animals contained motile spermatozoa from about 35-40 days of age. However, spermatozoa were detected in only 16 of 196 males kept in $8 \mathrm{~L}: 16 \mathrm{D}$ and it was these animals that had large tubular diameters and high testicular weight.

In Exp. 2 testicular development was determined by palpation. This method has been shown to be reliable in this species in our routine studies (see Hoffmann, 1973: Fig. 1). The mean values ( \pm s.e.m.) for 100 testes of each stage were $24.8 \pm 1.8 \mathrm{mg}$ for Stage N, $91.9 \pm 3.9 \mathrm{mg}$ for Stage S, 178.9 $\pm 4.7 \mathrm{mg}$ for Stage $M$ and $377 \cdot 1 \pm 6.9 \mathrm{mg}$ for Stage $\mathrm{L}$. All hamsters kept in $16 \mathrm{~L}: 8 \mathrm{D}(\mathrm{N}=42)$ and 40 or 


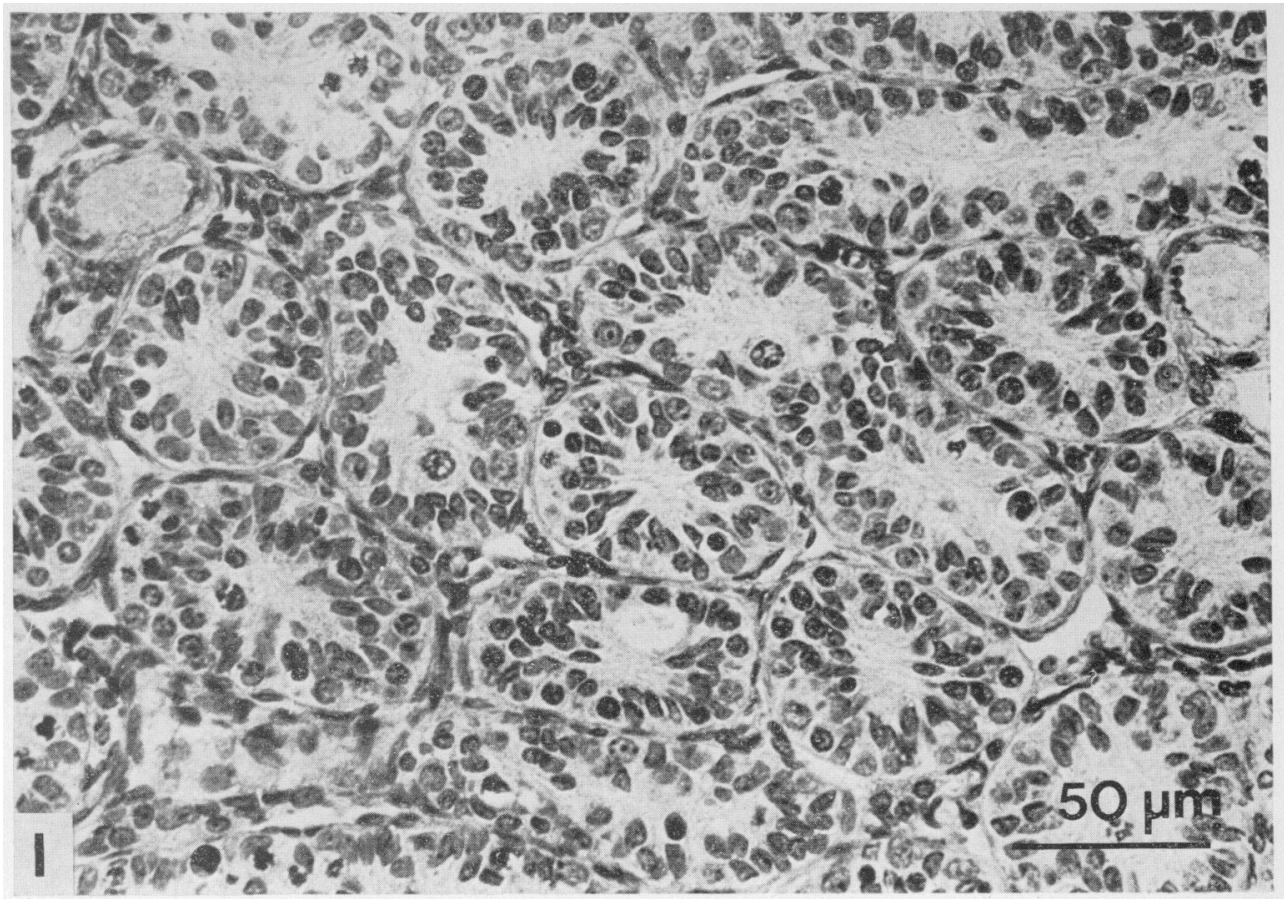

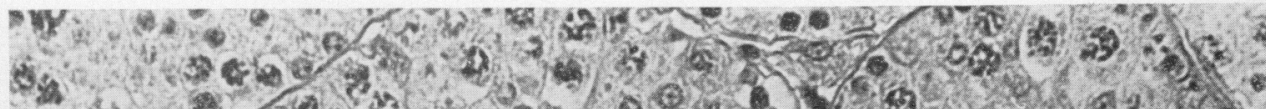

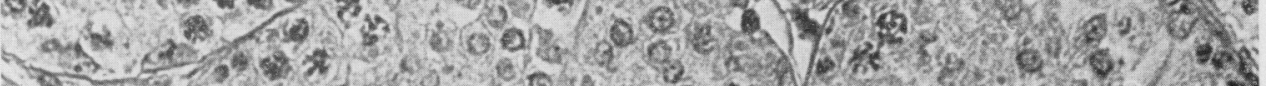

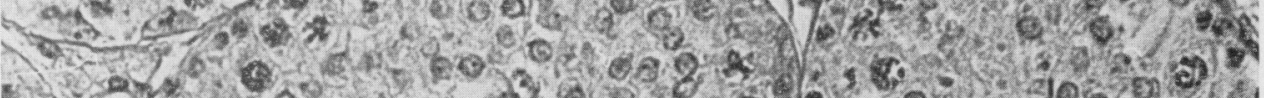

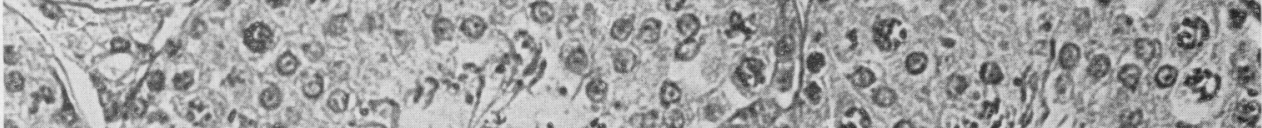

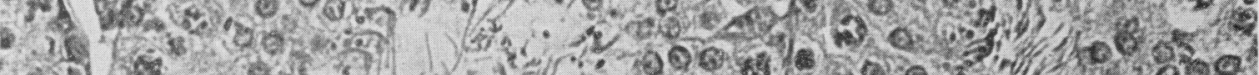

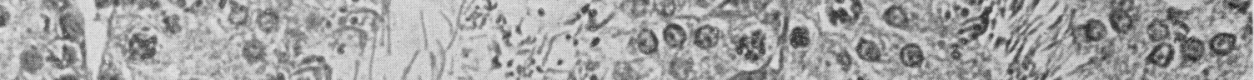

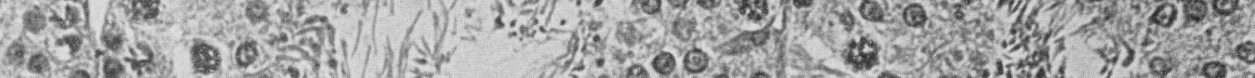

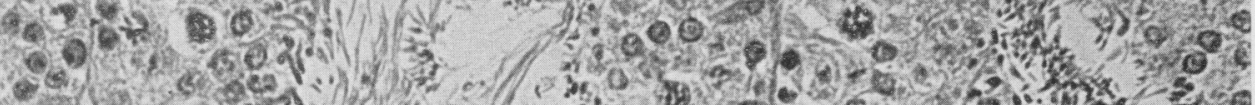

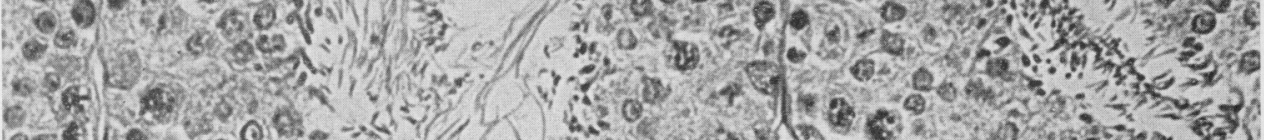

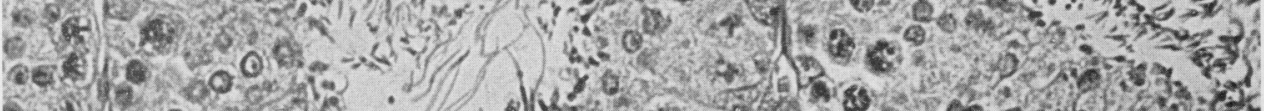

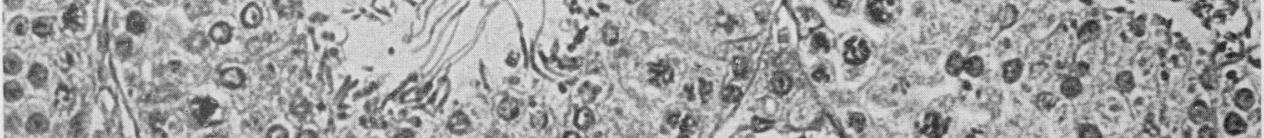

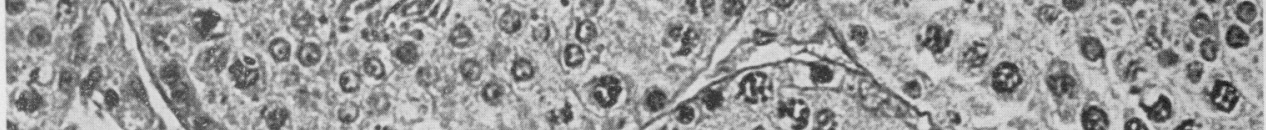

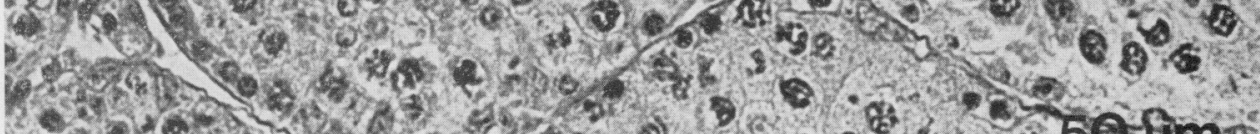

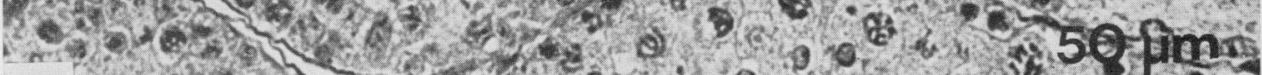

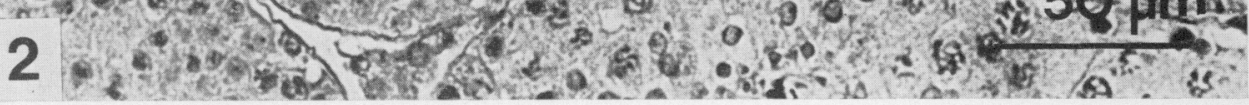

Microscopic appearance of the testes of Djungarian hamsters. Mayer's haemalum and cosin. $5 \mu m$ sections.

Fig. 1. Hamster raised in short photoperiods $18 \mathrm{~L}: 16 \mathrm{D})$ and killed at 72 days.

Fig. 2. Hamster raised in bong pholoperiods $116 \mathrm{~L}: 801$ and hilled al 35 da!n 
more days of age had large testes, corresponding to a state of full spermatogenesis, and remained in this condition up to the end of the experiment (Text-fig. 2a). In short photoperiods testes were not palpable (Stage N) in any of the 43 hamsters until at least 100 days of age (Text-fig. 2b). The first signs of further testicular development were observed between 116 and 164 days and full testicular size was reached at 158-207 days. These findings show that puberty finally occurs in spite of the short photoperiods, but that it is delayed for about 5 months compared to attainment of puberty at about 35 days in hamsters kept in long photoperiods.
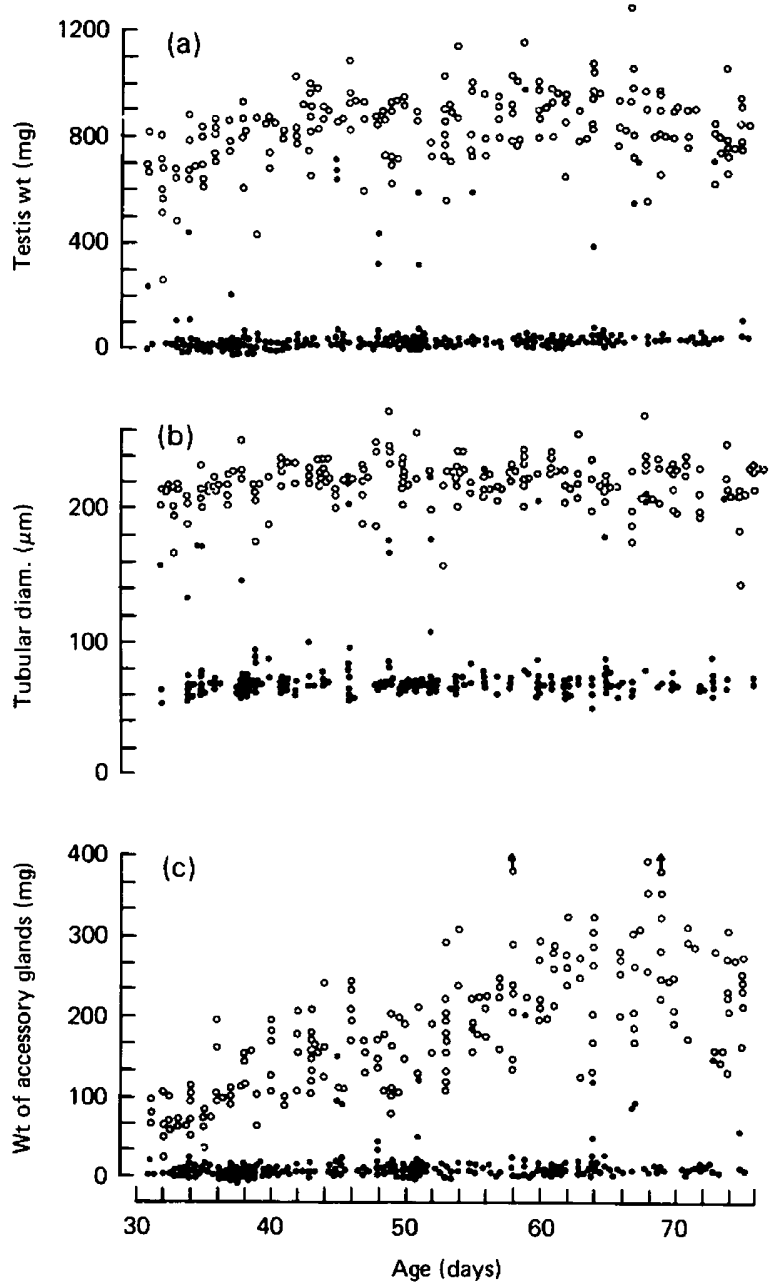

Text-fig. 1. The effect of raising Djungarian hamsters from birth in long $(16 \mathrm{~L}: 8 \mathrm{D}, 0)$ or short $(8 \mathrm{~L}: 16 \mathrm{D}, \bullet)$ photoperiods on (a) testicular weight, (b) seminiferous tubule diameter and (c) accessory gland weight.

Accessory glands. The accessory glands showed similar weight differences between animals raised in long and in short photoperiods (Text-fig. 1c). In long photoperiods, accessory gland weight increased up to an age of about 60 days, while no increase was found in $8 \mathrm{~L}: 16 \mathrm{D}$ animals up to 75 days of age.

Body weight. The weights for the animals weighed alive and dead in Exp. 1 are shown in Table 1. Males reared and kept in long photoperiods were significantly heavier from 21 days of age onward. The values for Exp. 2 are given in Text-fig. 3(a) for the 16L :8D animals, and in Text-fig. 3(b) for the hamsters maintained in short photoperiods. In long photoperiods, body weight increased steadily until 140-180 days when a final value was reached. In short photoperiods, body weight increased 
until 70-90 days, then plateaued or even declined until about 110-150 days, before increasing again to reach a final weight at 190-260 days. At 280 days of age body weight in the short-day hamsters was slightly higher $(46.7 \pm 0.7 \mathrm{~g}, \mathrm{~N}=43$ ) than in long photoperiods $(44.0 \pm 0.7 \mathrm{~g}, \mathrm{~N}=42 ; P<0.005)$.

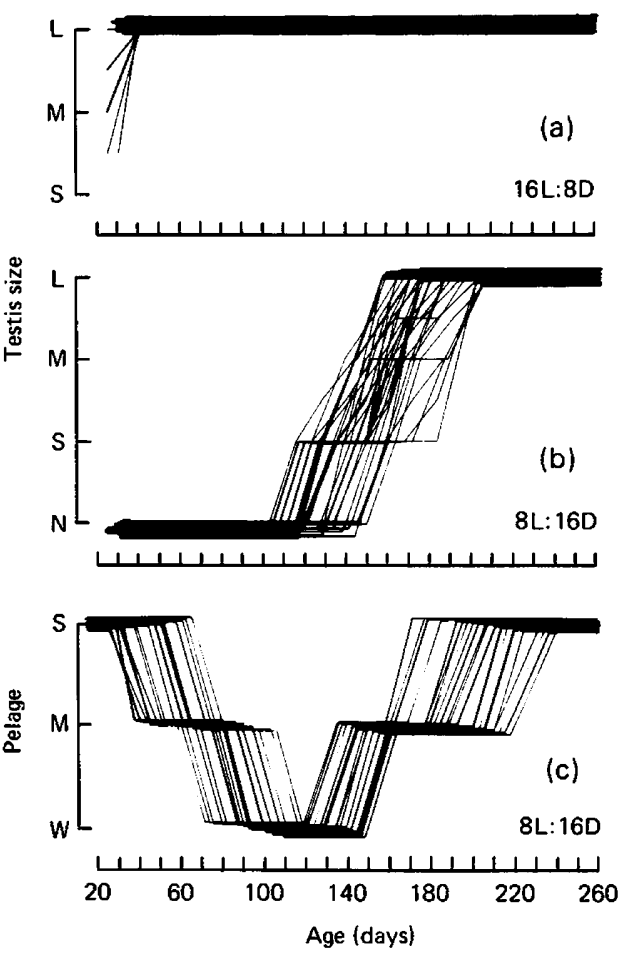

Text-fig. 2. Testicular size (determined by palpation at intervals of about 14 days) of Djungarian hamsters maintained from birth in (a) long or (b) short photoperiods: $N=$ not palpable; $S=$ small; $M=$ medium; $\mathrm{L}=$ large. (c) The pelage condition of the animals kept in short photoperiods $(\mathrm{S}=$ summer pelage; $\mathbf{M}=$ moult; $\mathbf{W}=$ winter pelage): all animals in the long photoperiod remained in the summer pelage.

Table 1. Body weight (mean \pm s.e.m.) of hamsters raised in long $(16 \mathrm{~L}: 8 \mathrm{D})$ or short $(8 \mathrm{~L}: 16 \mathrm{D})$ photoperiods

\begin{tabular}{|c|c|c|c|c|c|}
\hline \multirow{2}{*}{$\begin{array}{c}\text { Age } \\
\text { (days) }\end{array}$} & \multicolumn{2}{|c|}{$16 \mathrm{~L}: 8 \mathrm{D}$} & \multicolumn{2}{|c|}{$8 \mathrm{~L}: 16 \mathrm{D}$} & \multirow{2}{*}{$\begin{array}{l}\text { Significance } \\
\text { of difference }\end{array}$} \\
\hline & No. & Body wt (g) & No. & Body wt (g) & \\
\hline $21-25$ & 99 & $20.0 \pm 0.30$ & 76 & $17 \cdot 3 \pm 0.21$ & $P<0.001$ \\
\hline $26-30$ & 74 & $23.3 \pm 0.39$ & 63 & $21 \cdot 3 \pm 0.28$ & $P<0.001$ \\
\hline $31-35$ & 58 & $27.4 \pm 0.45$ & 83 & $21.9 \pm 0.31$ & $P<0.001$ \\
\hline $36-40$ & 60 & $29.3 \pm 0.41$ & 81 & $23.6 \pm 0.26$ & $P<0.001$ \\
\hline $41-45$ & 91 & $31 \cdot 3 \pm 0.29$ & 94 & $24.5 \pm 0.19$ & $P<0.001$ \\
\hline $46-50$ & 90 & $32.2 \pm 0.34$ & 63 & $25.8 \pm 0.33$ & $P<0.001$ \\
\hline $51-55$ & 110 & $34.0 \pm 0.29$ & 51 & $26.9 \pm 0.33$ & $P<0.001$ \\
\hline $56-60$ & 93 & $35.4 \pm 0.30$ & 31 & $28.0 \pm 0.52$ & $P<0.001$ \\
\hline $61-65$ & 95 & $34.5+0.43$ & 60 & $27.4 \pm 0.38$ & $P<0.001$ \\
\hline $66-70$ & 71 & $35.7 \pm 0.39$ & 27 & $29.4 \pm 0.52$ & $P<0.001$ \\
\hline $71-75$ & 77 & $35.5 \pm 0.43$ & 32 & $29.4 \pm 0.60$ & $P<0.001$ \\
\hline
\end{tabular}

Pelage colour. Up to an age of 30 days all animals in both photoperiods had summer pelage. This was maintained in the animals kept in $16 \mathrm{~L}: 8 \mathrm{D}$ throughout the experiment. In $8 \mathrm{~L}: 16 \mathrm{D}$, however, increasing numbers of hamsters began to moult into the winter pelage. In Exp. 1 the results were 
$22 \cdot 4 \%(\mathrm{~N}=163)$ at $31-40$ days, $54 \cdot 1 \%(\mathrm{~N}=157)$ at $41-50$ days, $58 \cdot 5 \%(\mathrm{~N}=82)$ at $51-60$ days, $73.6 \%$ $(\mathrm{N}=87)$ at $61-70$ days and $93.7 \%(N=54)$ at $71-80$ days. The pelage colour for Exp. 2 is given in Text-fig. 2(c). All the males in $8 \mathrm{~L}: 16 \mathrm{D}$ changed into the winter pelage starting between 37 and 78 days of age. The winter pelage was maintained until about 110-150 days of age and the full summer pelage was reached at $171-239$ days.
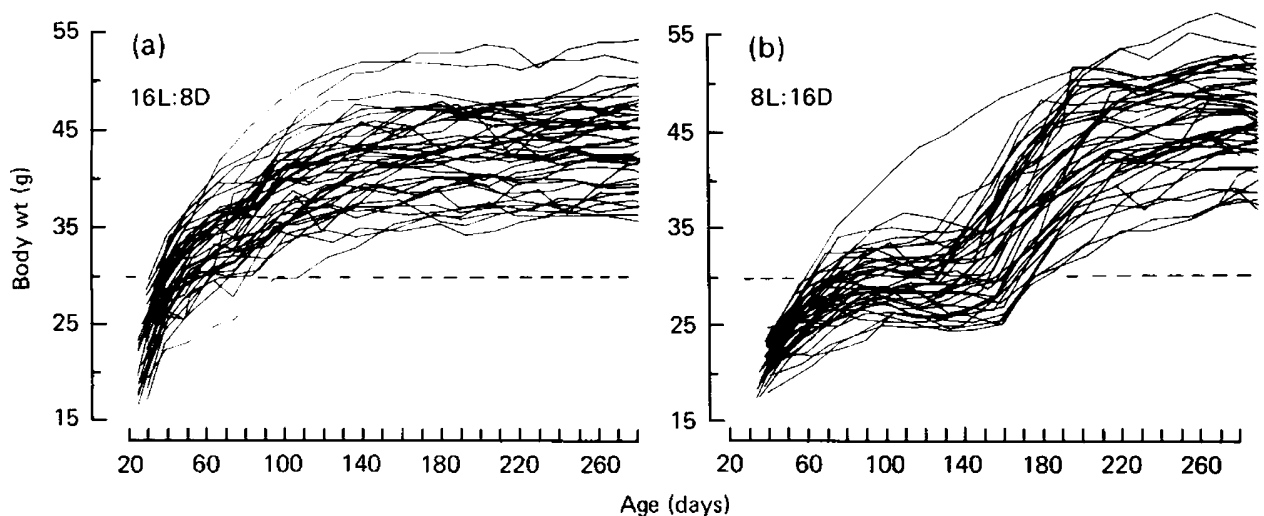

Text-fig. 3. Body weights of male Djungarian hamsters kept until 280 days of age in (a) long or (b) short photoperiods. Each animal is represented by one line. - - -, Body weight of adult in the winter.

\section{Discussion}

These results show that photoperiod markedly influences sexual maturation in Djungarian hamsters. In short photoperiods testes remain small and undeveloped up to an age of at least 100 days and closely resemble those found in adult males in winter, or after regression as a result of exposure to short photoperiods (Figala et al., 1973; Hoffmann, 1974). The observation that in a small proportion of young males testicular development starts early in spite of short photoperiods is also paralleled by findings in adults, a small proportion of which do not react to short natural or artificial photoperiods (Figala et al., 1973). The cause of this aberrant behaviour is not known. Body weight in the young males kept in short photoperiods soon reached a plateau at about $30 \mathrm{~g}$, a value which closely corresponds to the body weight of adults in winter condition (Figala et al. 1973; Hoffmann, 1973). All the young males raised in short photoperiods and not showing early testicular development moulted into winter pelage, as do adult hamsters exposed to artificial or natural short photoperiods (Figala et al., 1973; Hoffmann, 1978). In general, therefore, photoperiodic treatment of neonatal Djungarian hamsters leads to essentially the same effects as in adults, unlike the results with golden hamsters (see 'Introduction').

Maturation of the testes in juvenile Phodopus was not suppressed indefinitely by the short photoperiods. After about 130 days testes began to develop spontaneously and finally reached the size of those of the $16 \mathrm{~L}: 8 \mathrm{D}$ animals. Body weight and pelage colour showed similar spontaneous changes at about the same time. This corresponds to the behaviour of the adults in which spontaneous development of testes and moult into the summer pelage occur after some time in animals in which testicular regression and moult into winter pelage had been instigated by short photoperiods (Figala et al., 1973; Hoffmann, 1973). In adult golden hamsters spontaneous gonadal regrowth has been reported after involution induced by short photoperiods or by blinding (Hoffman, Hester \& Towns, 1965; Reiter, 1969, 1975).

A delay of puberty after exposure to short photoperiods from birth or from weaning has been reported for several species of the genus Microtus (Lecyk, 1963; Thibault et al., 1966; Clarke \& Kennedy, 1967; Grocock \& Clarke, 1974). Retardation of testicular development in these species, however, was less drastic than that in Phodopus. Clarke \& Kennedy (1967) report that the increase in body weight is greater in long than in short photoperiods. Effects of the light regimen on sexual 
development have also been found for the laboratory rat which is generally considered a continuous breeder, the most extreme results being reported by Fiske (1941). Hasler, Buhl \& Banks (1976) have reported that young lemmings (Dicrostonyx groenlandicus) raised from weaning in long or short photoperiods showed no difference in testicular development, whereas the short photoperiods induced moult into a whitish pelage in most of the juveniles. Body weights were significantly higher in short than in long photoperiods. The results of the present study of Phodopus and those of workers with other species demonstrate that there may be clear species differences in photoperiodic reaction and broad generalizations may be unwise.

In several mammals, including adult Phodopus, the pineal has been shown to participate in the photoperiodic mechanism (Reiter, 1973, 1974; Reiter, Vaughan, Vaughan, Sorrentino \& Donofrio, 1975; Hoffmann, 1978). The strong photoperiodic reaction in juvenile Phodopus suggests that these may be useful animals for the study of pineal function in photoperiodic regulation. First experiments with neonatal Phodopus demonstrate that the pineal is an integral part of the photoperiodic mechanism: pinealectomy at 2 days of age partly abolished the inhibitory effect of short photoperiods on testicular development (Brackmann \& Hoffmann, 1977).

The work was supported by the Schwerpunktprogramm "Biologie der Zeitmessung", Deutsche Forschungsgenmeinschaft.

\section{References}

Aschoff, J. (1955) Jahresgang der Fortpflanzung beim Warmblüter. Studium generale 8, 742-775.

Brackmann, M. \& Hoffmann, K. (1977) Pinealectomy and photoperiod influence testicular development in the Djungarian hamster. Naturwissenschaften 64, 341-342.

Chapman, D.I. (1970) Seasonal changes in the gonads and accessory glands of male mammals. Mammal Rev. 1, 231-248.

Clarke, J.R. \& Kennedy, J.P. (1967) Effect of light and temperature upon gonad activity in the vole (Microtus agrestis). Gen. comp. Endocr. 8, 474-488.

ELt.ot, J.E. (1974) Photoperiodic regulation of testis function in the golden hamster: relation to the circacadian system. Ph.D. thesis, University of Texas at Austin.

FARner, D.S., Lewis, R.A. \& DARden, T.R. (1973) Photoperiodic control mechanisms: homoiothermic animals. In Biology Data Book, 2nd edn, Vol. II, pp. 1047-1052. Eds P. L. Altman \& D. S. Dittmer. Fedn Am. Soc. exp. Biol., Bethesda.

Figala, J., HoffmanN, K. \& Goldau, G. (1973) Zur Jahresperiodik beim Dsungarischen Zwerghamster Phodopus sungorus Pallas. Oecologia 12, 89-118.

Fiske, V.M. (1941) Effect of light on sexual maturation, estrous cycles and anterior pituitary of the rat. Endocrinology 29, 189-196.

Flint, W.E. (1966) Die Zwerghamster der paläarktischen Fauna. A. Ziemsen, Wittenberg Lutherstadt.

Gaston, S. \& Menaker, M. (1967) Photoperiodic control of hamster testis. Science, N.Y. 158, 925-928.

Grocock, C.A. \& Clarke, J.R. (1974) Photoperiodic control of testis activity in the vole, Microtus agrestis. J. Reprod. Fert. 39, 337-347.

Hasler, J.F., Buhl, A.E. \& Banks, E.M. (1976) The influence of photoperiod on growth and sexual function in male and female collared lemmings (Dicrostonyx groenlandicus). J. Reprod. Fert. 46, 323-329.
Hoffman, R.A. \& Reiter, R.J. (1965) Pineal gland: influence on the gonads of male hamsters. Science, N. Y. 148, 1609-1611.

Hoffman, R.A., Hester, R.J. \& Towns, C. (1965) Effect of light and temperature on the endocrine system of the golden hamster (Mesocricetus auratus Waterhouse). Comp. Biochem. Physiol. 15, 525533.

HoffmanN, K. (1973) The influence of photoperiod and melatonin on testis size, body weight, and pelage colour in the Djungarian hamster (Phodopus sungorus). J. comp. Physiol. 85, 267-282.

HoffmanN, K. (1974) Testicular involution in short photoperiods inhibited by melatonin. Naturwissenschaften 61, 364-365.

Hoffmann, K. (1978) Die Funktion des Pineals bei der Jahresperiodik der Säuger. Nova Acta Leopoldina (in press).

Hoffmann, K. \& Küderling, I. (1975) Pinealectomy inhibits stimulation of testicular development by long photoperiods in a hamster (Phodopus sungorus). Experientia 31, 122-123.

Hoffmann, K. \& Küderling, I. (1977) Antigonadal effects of melatonin in pinealectomized Djungarian hamsters. Naturwissenschaften 64, 339-340.

LECYK, M. (1963) The effect of short daylight on sexual maturation in young individuals of the vole, Microtus arvalis PALL. Zoologica Pol. 13, 77-86.

Lincoln, G.A. \& MacKinnon, P.C.B. (1976) A study of seasonally delayed puberty in the male hare, Lepus europeaus. J. Reprod. Fert. 46, 123-128.

ReITER, R.J. (1969) Pineal function in long term blinded male and female golden hamsters. Gen. comp. Endocr. 12, 460-468.

ReITER, R.J. (1973) Comparative physiology: pineal gland. A. Rev. Physiol. 35, 305-328.

REITER, R.J. (1974) Circannual reproductive rhythms in mammals related to photoperiod and pineal function: a review. Chronobiologia 1, 365-395. 
REITER, R.I. (1975) Exogenous and endogenous control of the annual reproductive cycle in the male golden hamster: participation of the pineal gland. J. exp. Zool. 191, 111-119.

Reiter, R.J., Sorrentino, S. \& Hoffman, R.A. (1970) Early photoperiodic conditions and pineal antigonadal function in male hamsters. Int. J. Fert. 15, 163-170.

Reiter, R.J., Vaughan, M.K., Vaughan, G.M., Sorrentino, S. \& Donofrio, R.J. (1975) The pineal gland as an organ of internal secretion. In Frontiers of Pineal Physiology, pp. 54-174. Ed. M. D. Altschule. MIT Press, Cambridge, Massachusetts.

SADLEIR, R.M.F.S. (1969) The Ecology of Reproduction in Wild and Domestic Mammals. Methuen, London.

Thibault, C., Courot, M., Martinet, L., Mauleon, P., du Mesnil. du Buisson, F., Ortavant, R., PelleTIER, J. \& SIGNORET, J.P. (1966) Regulation of breeding season and estrous cycles by light and external stimuli in some mammals. J. Anim. Sci. 25 (Suppl.), 119-142.

Received 12 September 1977 